\title{
Metaplastic breast carcinoma with components of undifferentiated sarcomatous carcinoma and invasive ductal carcinoma: a case report with review of the literature
}

\author{
Jeffrey D. Poot ${ }^{1}$, Alison L. Chetlen ${ }^{1}$, Zhaohai Yang ${ }^{2}$ \\ 1. Department of Radiology, Penn State Milton S Hershey Medical Center, Hershey, PA, United States. 2. Department of \\ Pathology, Penn State Milton S Hershey Medical Center, Hershey, PA, United States. \\ Correspondence: J effrey D. Poot, D.O. Address: Department of Radiology, Penn State Milton S Hershey Medical Center, \\ 500 University Drive, Hershey, PA 17033, United States. E-mail: jpoot@hmc.psu.edu
}

Received: March 4, 2014

DOI : $10.5430 /$ crcp.v1n2p117
Accepted: May 5, 2014

URL: http://dx.doi.org/10.5430/crcp.v1n2p117

\section{Abstract}

Metaplastic breast carcinoma (MBC) is a rare type of breast carcinoma that includes a heterogeneous group of tumors that tend to have mixed and often mesenchymal differentiation. Several variants have been described; however in terms of prognosis, these different variants are referred to as a single entity of MBC. Awareness of this tumor is important as treatment options for patients with MBC differ from those of typical breast carcinomas. In this report, a 58-year-old female presented with a rapidly enlarging breast mass of three-month duration, which was diagnosed as MBC. This case illustrates important points in the diagnosis and treatment of patients with MBC. Clinicopathologic and radiologic features are discussed with review of the literature.

\section{Key words}

Metaplastic carcinoma, Breast neoplasms, Diagnostic imaging, Pathology, Radiology

\section{I ntroduction}

Metaplastic breast carcinoma (MBC) includes a heterogeneous group of neoplasms and the incidence is reported to be as low as $0.5 \%{ }^{[1]}$ to less than $5 \%$ of breast carcinomas ${ }^{[2]}$. MBC tend to have a mixed epithelial and mesenchymal differentiation. They are considered to be ductal carcinomas that undergo metaplasia from a glandular growth pattern ${ }^{[2,3]}$. Five variants of $\mathrm{MBC}$ were initially suggested by Wargotz et al. ${ }^{[4-8]}$, which included matrix-producing carcinoma, squamous cell carcinoma, spindle cell carcinoma, carcinosarcoma, and metaplastic carcinoma with osteoclastic giant cells. An additional low-grade fibromatosis-like tumor variant has also been described ${ }^{[9,10]}$.

\section{Case presentation}

We report a case of invasive MBC consisting both of sarcomatous as well as ductal carcinoma components in a 58-yearold woman who had no pertinent past medical history. The patient presented with an enlarging right breast mass of three 
months duration, with the mass beginning in the superior pole of the breast. Presenting symptoms included fevers, waxing and waning swelling, and intermittent reddening of the skin (see Figure 1 for clinical photograph). Initial mammogram demonstrated a large dense mass of $22 \mathrm{~cm}$ completely replacing the normal right breast fibroglandular tissue. Ultrasound was performed with subsequent biopsy (see Figure 2 for ultrasound image).

Figure 1. Clinical photograph of enlarged right breast mass.

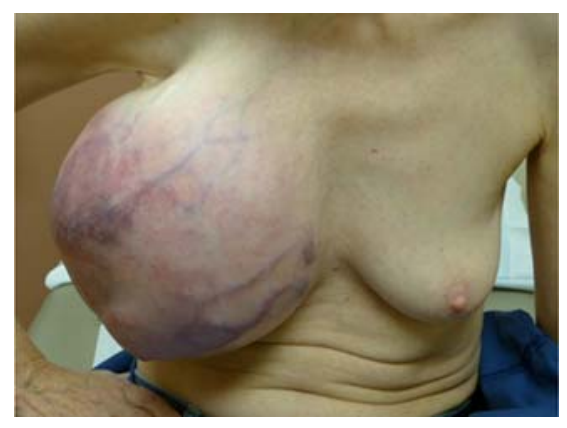

Figure 2. Ultrasound image of the breast demonstrates an irregular round mass with anti-parallel orientation and indistinct margins with heterogeneous echotexture. Posterior acoustic enhancement was seen. On Power Doppler imaging, the mass was found to be markedly hypervascular.

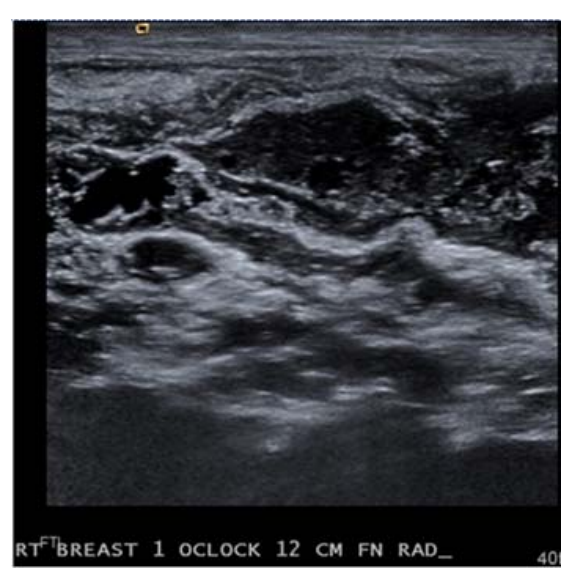

\section{Differential diagnosis}

The differential diagnosis of this rapidly enlarging mass in this postmenopausal female included malignant phyllodes tumor, lymphoma, sarcoma, and breast cancer ${ }^{[11]}$. Phyllodes tumors, much less common than fibroadenomas, are typically larger in size than fibroadenomas, with a presenting age of 15-20 years older than fibroadenoma ${ }^{[1]}$. Primary breast lymphoma, only accounts for $0.4 \%-0.5 \%$ of all breast malignancies, usually presents as a painless mass with median age of presentation 60-65 years old. Primary breast sarcoma, such as angiosarcoma usually presents as soft friable masses with bluish discoloration and may be quite large at presentation (average size $5 \mathrm{~cm}$ ). They may arise de novo or following irradiation to the breast ${ }^{[1]}$. Careful histological examination and immunohistochemistry following core needle biopsy were vital in making the correct diagnosis.

The mass was found to be markedly vascular on diagnostic ultrasound and during the biopsy, so computed tomography angiography (CTA) of the chest was performed in preparation for embolization prior to surgery (see Figure 3 for CTA image showing hypervascularity). Positron emission tomography-computed tomography (PET-CT) performed prior to mastectomy did not show evidence of metastatic disease. The patient underwent radical mastectomy removing the majority of the pectoralis major muscle and a portion of the pectoralis minor muscle with axillary node dissection of levels 1 and 2 lymph nodes. Pathologic examination revealed a large firm tumor measuring $22 \mathrm{~cm} \times 14.5 \mathrm{~cm}$, which essentially replaced the breast. The cut surface showed a variegated appearance with necrosis, hemorrhage, and cystic degeneration (see Figure 4). Microscopically, the vast majority of the tumor showed high-grade undifferentiated spindle cell/ sarcomatous component with high mitotic activity, rich vasculature, and geographic necrosis (see Figure 5A). A focal chondrosarcomatous area was noted. Small areas of epithelial/ductal carcinoma component were intimately surrounded by sarcomatous tumor cells (see Figure 5B). Focal squamous differentiation was also present, with transition between ductal 
and squamous carcinoma, as well as between squamous and spindle cell/sarcomatous carcinoma (see Figure 5C). An extensive panel of immunohistochemical stains was performed on the initial biopsy, and selective markers were repeated on the resection specimen. The epithelial/ductal carcinoma component was diffusely positive for pan-keratin AE1/AE3, low molecular weight keratin Cam5.2, and high molecular weight keratin 34ßE12 (see Figure 6A); patchy variably positive for ER (see Figure 6B); focally positive for high molecular weight keratin CK5/6 (see Figure 6C) and p63 (see Figure 6D). Of note, CK5/6 and p63 appeared to label the tumor cells per se, especially where there was squamous differentiation. Along with negative staining for smooth muscle myosin heavy chain marker, no myoepithelial layer was identified in these epithelial/glandular structures, thus supporting the interpretation of invasive ductal carcinoma (IDC) component. None of the above markers stained the spindle cell/sarcomatous component. S100 was focally positive in the sarcomatous component, mostly in areas with chondrosarcomatous differentiation. CD45, CD34, myeloperoxidase, CD117, and HMB45 were all negative in the tumor cells of both ductal carcinoma and sarcomatous components. A diagnosis of metaplastic carcinoma was rendered. The tumor invaded into the skeletal muscle, with a focal positive posterior margin. ER/PR was positive in the ductal carcinoma component ( $75 \%$ cells with moderate to strong nuclear staining) and negative in the sarcomatous component. HER2/neu was negative in both components. Thus, the spindle cell/sarcomatous component is essentially triple-negative. All 22 lymph nodes were negative.

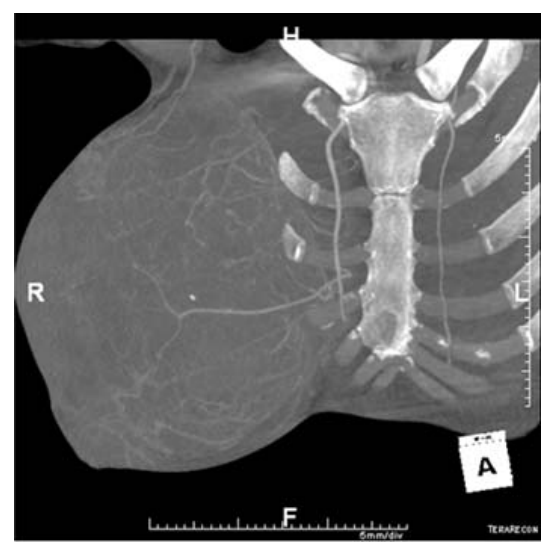

Figure 3. Computed tomography angiography image of the chest demonstrates large moderately enhancing right breast mass with extensive vascularity.

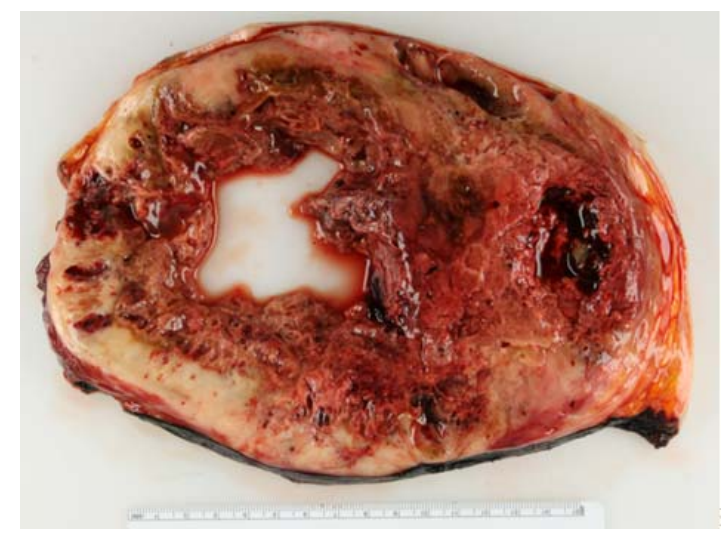

Figure 4. Gross photograph of the resected breast mass. This is a well-circumscribed mass, which essentially replaces the breast. The cut surface shows necrosis, hemorrhage, and cystic degeneration.


Figure 5. Microscopic images of the breast tumor. A. The predominant component resembles a high-grade undifferentiated sarcoma, with abundant mitoses and rich vasculature. B. The minor component shows a typical ductal carcinoma, which is also surrounded by sarcomatous cells. C. Focally, there is squamous differentiation, with intimate transition between squamous and ductal carcinoma, as well as between squamous and spindle cell/sarcomatous carcinoma (Original magnification $\times 200$ ).

Published by Sciedu Press 


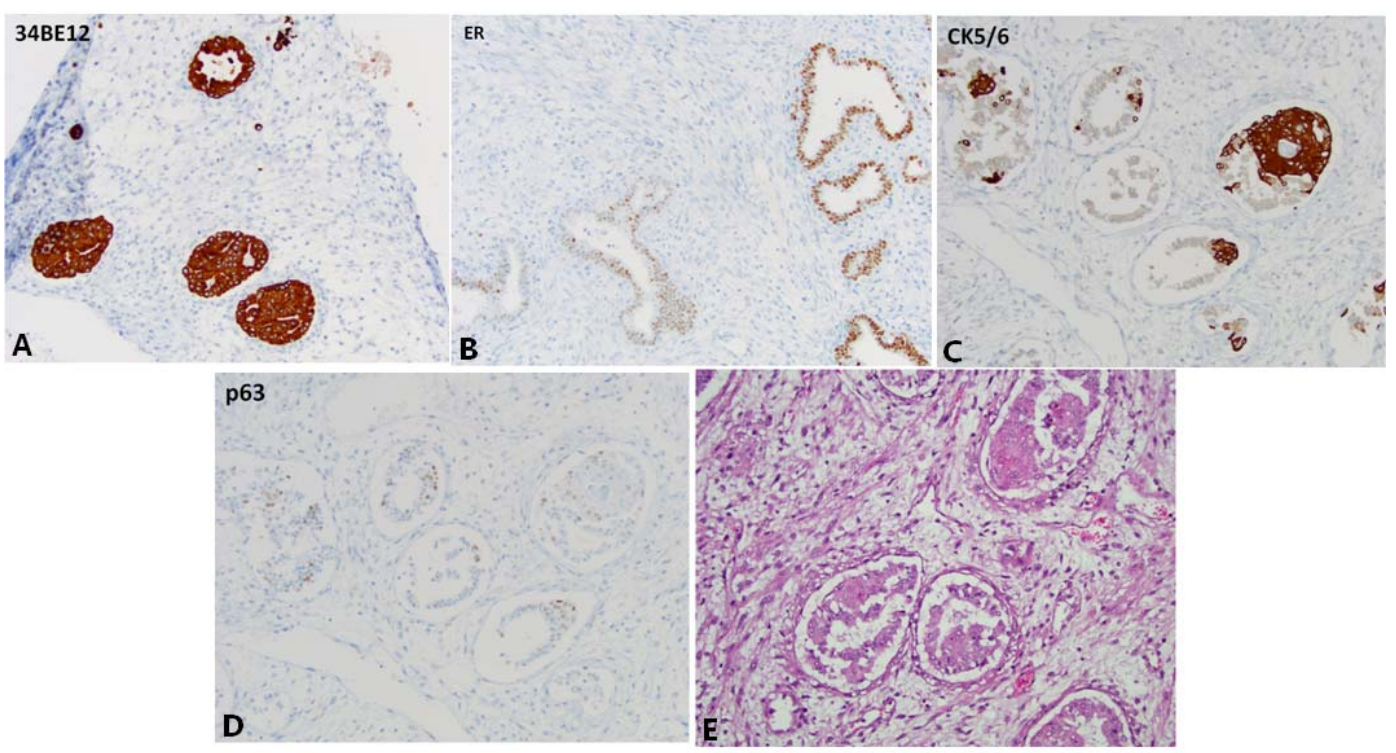

Figure 6. Immunohistochemical staining of the metaplastic carcinoma. The epithelial/ductal carcinoma component is diffusely positive for high molecular weight keratin 34BE12 (A), patchy variably positive for ER (B), focally positive for high molecular weight keratin CK5/6 (C) and p63 (D). The spindle cell/sarcomatous component is negative for all four markers. The corresponding H\&E stain is shown in E (Original magnification $\times 200$ ).

The patient underwent a chemotherapy regimen consisting of docetaxel $75 \mathrm{mg} / \mathrm{m}^{2}$ and cisplatin $75 \mathrm{mg} / \mathrm{m}^{2}$ every 3 weeks $\times$ 4 cycles. This was followed by cyclophosphamide $500 \mathrm{mg} / \mathrm{m}^{2}$, doxorubicin $50 \mathrm{mg} / \mathrm{m}^{2}$ and cisplatin $50 \mathrm{mg} / \mathrm{m}^{2}$ every 3 weeks $\times 4$ cycles (although cisplatin was discontinued in the last cycle due to worsening peripheral neuropathy). A plan was made for radiation therapy with a possibility of subsequent hormonal therapy. Prior to that a repeat PET-CT showed a large left adrenal mass, bilateral lung nodules, vertebral body lesion at L2, and peritoneal seeding. Biopsy of the left adrenal mass showed a poorly differentiated malignancy similar to the prior breast tumor. Systemic chemotherapy was no longer an option for the patient, who was given palliative radiotherapy of $200 \mathrm{cGy}$ to the left abdomen in a single fraction. After the radiation treatment, the patient's condition deteriorated and she was transferred to hospice for palliative care where she passed away.

\section{Discussion}

\subsection{Clinical features of metaplastic carcinoma}

Metaplastic breast carcinomas are rare and typically seen in women older than 50 years of age ${ }^{[3-8]}$. Clinical signs may include rapidly growing breast mass. Numerous studies suggest that $\mathrm{MBC}$ tends to present with much larger tumors than conventional invasive ductal carcinoma ${ }^{[12-17]}$. Axillary lymph node is infrequently involved which is reported in $6 \%-40 \%$ of cases ${ }^{[1,3,5,6,18,19]}$. Local and/or distant metastases can be seen in greater than $50 \%$ of these tumors within five years, and there is poor prognosis with recurrence ${ }^{[18]}$. Worse outcome is seen with patients having skin invasion, age younger than 39 at presentation, and squamous cell carcinoma in the lymph nodes ${ }^{[20]}$. Hematogenous tumor spread is more common than lymphatic spread, with bone and lung as the most commonly involved distant sites ${ }^{[2,5,6,21]}$. MBC can be difficult to diagnose prior to surgical resection; in a study by Park et al. core needle biopsy correctly diagnosed MBC in only 1 of 24 biopsies $^{[13]}$.

In a systematic review of 15 studies on MBC, Toumi et al. found that the typical method of treatment was mastectomy $(66.9 \%)$ in combination with chemotherapy $(57 \%)$ and radiation therapy $(47 \%)^{[22]}$. It was also noted that adjuvant hormonal therapy was given to $7 \%$ of patients ${ }^{[22]}$. No survival benefit was seen in patients with distant metastasis treated 
with chemotherapy or radiation ${ }^{[6]}$. The response of MBC to systemic chemotherapy has been poor. One study reported an $83 \%$ progression in those receiving neoadjuvant chemotherapy ${ }^{[23]}$ with a complete response rate of up to $10 \%{ }^{[24]}$. Chen et al. reported that there was very minimal response to anthracycline, vinorelbine, or cyclophosphamide-based chemotherapy, with modest response to taxane-based chemotherapy ${ }^{[23]}$. Additional studies have also shown poor response to neoadjuvant chemotherapy for MBC with standard regimens ${ }^{[25,26]}$. Because of the low response rate to chemotherapy, surgical resection should be the treatment of choice regardless of tumor size. Regarding the type of surgery, there is no difference in overall or disease-free survival between patients undergoing modified radical mastectomy and breast conservation therapy ${ }^{[28,29]}$. Nevertheless, there is increased risk of tumor recurrence in MBC as compared with invasive ductal or lobular carcinoma ${ }^{[19,20,27]}$. A study by Bae et al. compared MBC and IDC triple-negative breast cancer patients and found a poorer prognosis in patients with $\mathrm{MBC}$ with nodal metastases ${ }^{[30]}$.

The subtype of metaplastic breast carcinoma was not shown to have an effect on overall outcome ${ }^{[20]}$. Oberman suggested that metaplastic breast carcinoma be considered a single entity in terms of prognosis ${ }^{[31]}$ while Wargotz, et al. suggested prognosis may be related to specific subtypes ${ }^{[4-8]}$. There is worse overall survival in MBC compared to conventional breast carcinoma ${ }^{[6,12]}$. Stage IV disease was more commonly seen in MBC than invasive ductal carcinoma $(10.3 \%$ vs. $0.9 \%)^{[1]}$. Triple-negative breast cancer is more common in MBC than IDC ( $84 \%$ vs. $\left.20.1 \%\right)$, as characterized by a lack of estrogen receptor (ER), progesterone receptor (PR), and HER2/neu over-expression ${ }^{[1]}$. Triple-negative breast carcinoma is a heterogeneous group, which has been subdivided to be basal or non-basal phenotypes based on expression of CK5/6 and EGFR ${ }^{[32]}$. The basal phenotype, was originally defined as being associated with CK5/6 positivity alone, but Foulkes et al. suggests this can be extended to include high cyclin E/low p27/positive P53/positive GMP staining ${ }^{\text {[33] }}$. Furthermore, Foulkes et al. indicates that CK5/6-positive alone indicates a more than five times greater likelihood of identifying a BRCA1 mutation ${ }^{[33]}$. Hashmi et al. proposed that young patients with triple-negative breast cancers including metaplastic carcinoma should be investigated for risk factors including BRCA1 mutations ${ }^{[34]}$. A study by Reis-Filho et al. demonstrated $91 \%$ basal-like tumor profile in patients with metaplastic breast carcinoma (defined as ER negative, HER2/neu negative, EGFR positive and/or CK5/6 positive) ${ }^{[35]}$. Epidermal growth factor receptor (EGFR) immunoreactivity was found in $70 \%$ of MBCs in a study by Leibl ${ }^{[36]}$. Given the ineffectiveness of conventional therapies, Leibl suggested that with EGFR being positive, targeted protein kinase inhibitors such as gefitinib could be effective ${ }^{[36]}$.

\subsection{Pathologic features of metaplastic carcinoma}

There are distinct histological characteristics in the six subtypes of MBC. Matrix-producing carcinoma has abundant cartilaginous and/or osseous matrix with absence of the spindle cell component ${ }^{[4]}$. Spindle cell carcinoma predominantly shows spindle cell component or cells forming poorly cohesive sheets, which resembles low-grade sarcoma or reactive process such as granulation tissue. This has a 5-year survival rate of $64 \%{ }^{[5,19]}$. Carcinosarcoma encompasses neoplasms containing both malignant epithelium and stroma with 5 -year survival rate of $49 \%{ }^{[6,19]}$. Squamous cell carcinoma (SCC) of ductal origin has infiltrating carcinoma with polygonal cells, eosinophilic cytoplasm, and possible keratin pearl formation, which is solely squamous. SCC has a 5 -year survival rate of $63 \%{ }^{[7,19]}$. Metaplastic carcinoma with osteoclastic giant cells mixed with either an intraductal or infiltrating carcinoma with either spindle cell or sarcomatous stroma has a 5-year survival rate of $68 \%$. An additional subtype has been described as a low-grade fibromatosis-like tumor ${ }^{[9,10]}$. Metaplastic carcinomas are typically ER, PR, and HER2/neu negative. A cytokeratin panel can help distinguish cases of metaplastic breast carcinoma from phyllodes tumors, primary sarcomas, and fibromatoses in most cases ${ }^{[37]}$.

\subsection{Radiologic features of metaplastic carcinoma}

There are several mammographic features suggestive of MBC. A palpable breast mass may present with a high density lesion on mammography. The margins may be circumscribed, obscured, spiculated, or irregular ${ }^{[1-3,27,38,39]}$. A breast lesion with a more benign appearance, including round or oval shape and well circumscribed margins can be seen in MBC, as compared with the typical appearance of invasive ductal carcinoma ${ }^{[39]}$. In the rare cases when calcification is seen, the typical morphology of the calcifications includes coarse heterogeneous, punctate, amorphous, or fine pleomorphic ${ }^{[1,27]}$. Architectural distortion can also be seen in $\mathrm{MBC}{ }^{[1]}$. Uncommon features in metaplastic carcinomas include irregular Published by Sciedu Press 
shape, spiculated margins, and segmentally distributed pleomorphic calcifications. The spindle cell subtype of MBC can present with circumscribed margins. The squamous cell variant of MBC may present with more cystic components ${ }^{[1]}$. MBC with chondroid differentiation can be suggested when an area of intense uptake of Technetium 99-m methylene diphosphonate (MDP) on nuclear bone scintigraphy is observed ${ }^{[27]}$.

There are also several sonographic features suggestive of MBC. It may present as a heterogeneous, hypoechoic solid mass or a mixed cystic and solid mass ${ }^{[1,3,27,39]}$. The cystic components may be related to cystic degeneration and/or necrosis ${ }^{[3,18,40]}$. The descriptions of shape and margins on ultrasound are nonspecific as several shapes have been described, including oval, round, lobular, or irregular. Several types of margins have also been described, which include circumscribed, microlobulated, irregular, or indistinct. Posterior acoustic enhancement in MBC can help differentiate it

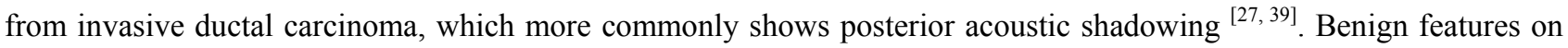
mammography and ultrasound are often seen with MBC in contradiction to invasive ductal carcinoma ${ }^{[39]}$.

There are several magnetic resonance imaging (MRI) features that are found in MBC. MBC often appears as an irregular enhancing mass with spiculated margins, isointense to hyperintense $\mathrm{T} 2$ signal, and isointense to hypointense $\mathrm{T} 1$ signal ${ }^{[27,38]}$. T2 hyperintense signal is reported in $91 \%$ of cancers with $\mathrm{MBC}^{[38]}$, likely related to necrosis or mucoid production. Invasive ductal carcinoma with abundant necrosis along with mucinous carcinoma subtype can also show T2 hyperintensity ${ }^{[38]}$. There are several enhancement characteristics of the internal components of MBC which have been described as ring-like, homogeneous, heterogeneous, or non-enhancing. Type II or III enhancement kinetics are frequently seen in MBC.

\section{Summary}

Our patient shared several common features of MBC. She was over 50 years old, presented clinically with a rapidly growing breast mass, and did not have axillary node involvement on initial diagnosis. Our patient had a high density mass on mammography with posterior acoustic enhancement seen on sonography. A diagnosis of MBC was given and, accordingly, surgery was performed despite the large size of $22 \mathrm{~cm}$, with preoperative embolization to reduce the risk of intraoperative blood loss. The sarcomatous component of her tumor was triple negative (ER, PR, HER2/neu negative). She had disease progression with distant metastases despite systemic chemotherapy within eight months of diagnosis, which occurs in greater than $50 \%$ of patients within five years.

Metaplastic breast carcinoma remains a rare but important entity in the diagnosis of breast lesions. Clinical, pathological, and radiological features can help suggest or differentiate MBC from typical breast carcinomas and other entities. Currently, the choice of treatment is surgical resection and the prognosis is generally poor.

\section{Conflict of interests}

Authors disclose no potential conflict of interests.

\section{References}

[1] J.M. Park, B.K. Han, W.K. Moon, Y.H. Choe, S.H. Ahn, G. Gong. Metaplastic carcinoma of the breast: mammographic and sonographic findings. Journal of clinical ultrasound. 2000; 28: 179-186. http://dx.doi.org/10.1002/(SICI)1097-0096(200005)28:4<179::AID-JCU5>3.0.CO;2-Y

[2] H.A. Oberman. Metaplastic carcinoma of the breast: a clinicopathologic study of 29 patients. The American journal of surgical pathology. 1987; 11: 918-929. PMid: 2825549. http://dx.doi.org/10.1097/00000478-198712000-00002

[3] I.i. Günhan-Bilgen, A. Memis, E.E. Ustün, O. Zekioglu, N. Ozdemir. Metaplastic carcinoma of the breast: clinical, mammographic, and sonographic findings with histopathologic correlation. American Journal of Roentgenology. 2002; 178: 1421-1425. PMid: 12034610. http://dx.doi.org/10.2214/ajr.178.6.1781421 
[4] E.S. Wargotz, H.J. Norris. Metaplastic carcinomas of the breast. I. Matrix-producing carcinoma. Human pathology. 1989; 20: 628-635. http://dx.doi.org/10.1016/0046-8177(89)90149-4

[5] E.S. Wargotz, P.H. Does, H.J. Norris. Metaplastic carcinomas of the breast. II. Spindle cell carcinoma. Human pathology. 1989; 20: 732-740. http://dx.doi.org/10.1016/0046-8177(89)90065-8

[6] E.S. Wargotz, H.J. Norris. Metaplastic carcinomas of the breast. III. Carcinosarcoma. Cancer. 1989; 64: $1490-1499$. http://dx.doi.org/10.1002/1097-0142(19891001)64:7<1490::AID-CNCR2820640722>3.0.CO;2-L

[7] E.S. Wargotz, H.J. Norris. Metaplastic carcinomas of the breast. IV. Squamous cell carcinoma of ductal origin. Cancer. 1990; 65: 272-276. http://dx.doi.org/10.1002/1097-0142(19900115)65:2<272::AID-CNCR2820650215>3.0.CO;2-6

[8] E.S. Wargotz, H.J. Norris. Metaplastic carcinomas of the breast: V. Metaplastic carcinoma with osteoclastic giant cells. Human pathology. 1990; 21: 1142-1150. http://dx.doi.org/10.1016/0046-8177(90)90151-T

[9] H. Gobbi, J.F. Simpson, A. Borowsky, R.A. Jensen, D.L. Page. Metaplastic breast tumors with a dominant fibromatosis-like phenotype have a high risk of local recurrence. Cancer. 1999; 85: 2170-2182. http://dx.doi.org/10.1002/(SICI)1097-0142(19990515)85:10<2170::AID-CNCR11>3.0.CO;2-X

[10] N. Sneige, H. Yaziji, S.R. Mandavilli, E.R. Perez, N.G. Ordonez, A.M. Gown, et al. Low-grade (fibromatosis-like) spindle cell carcinoma of the breast. The American journal of surgical pathology. 2001; 25: 1009-1016. PMid: 11474284. http://dx.doi.org/10.1097/00000478-200108000-00004

[11] M. Gary, P.H. Tan, P.C. Lui, T.C. Putti. Spindle cell lesions of the breast-the pathologic differential diagnosis. Breast cancer research and treatment. 2008; 109: 199-207. PMid: 17636400. http://dx.doi.org/10.1007/s10549-007-9652-2

[12] D. Rayson, A. Adjei, V. Suman, L. Wold, J. Ingle. Metaplastic breast cancer: prognosis and response to systemic therapy. Annals of Oncology. 1999; 10: 413-419. PMid: 10370783. http://dx.doi.org/10.1023/A:1008329910362

[13] H.S. Park, S. Park, J.H. Kim, J.-H. Lee, S.-Y. Choi, B.-W. Park, et al. Clinicopathologic features and outcomes of metaplastic breast carcinoma: comparison with invasive ductal carcinoma of the breast. Yonsei medical journal. 2010; 51: 864-869. PMid: 20879052. http://dx.doi.org/10.3349/ymj.2010.51.6.864

[14] J.D. Beatty, M. Atwood, R. Tickman, M. Reiner. Metaplastic breast cancer: clinical significance. The American journal of surgery. 2006; 191: 657-664. PMid: 16647355. http://dx.doi.org/10.1016/j.amjsurg.2006.01.038

[15] H. Gutman, R.E. Pollock, N.A. Janjan, D.A. Johnston. Biologic distinctions and therapeutic implications of sarcomatoid metaplasia of epithelial carcinoma of the breast. Journal of the American College of Surgeons. 1995; 180: 193-199. PMid: 7850054.

[16] P. Barnes, R. Boutilier, D. Chiasson, D. Rayson. Metaplastic breast carcinoma: clinical-pathologic characteristics and HER2/neu expression. Breast cancer research and treatment. 2005; 91: 173-178. PMid: 15868445. http://dx.doi.org/10.1007/s10549-004-7260-y

[17] C.M. Pezzi, L. Patel-Parekh, K. Cole, J. Franko, V.S. Klimberg, K. Bland. Characteristics and treatment of metaplastic breast cancer: analysis of 892 cases from the National Cancer Data Base. Annals of Surgical Oncology. 14: 166-173. PMid: 17066230. http://dx.doi.org/10.1245/s10434-006-9124-7

[18] R.J. Brenner, R.R. Turner, V. Schiller, R.D. Arndt, A. Giuliano. Metaplastic carcinoma of the breast. Cancer. 1998 ; 82: $1082-1087$. http://dx.doi.org/10.1002/(SICI)1097-0142(19980315)82:6<1082::AID-CNCR11>3.0.CO;2-2

[19] A. Luini, M. Aguilar, G. Gatti, R. Fasani, E. Botteri, J.A.D. Brito, et al. Metaplastic carcinoma of the breast, an unusual disease with worse prognosis: the experience of the European Institute of Oncology and review of the literature. Breast cancer research and treatment. 2007; 101: 349-353. PMid: 17009109. http://dx.doi.org/10.1007/s10549-006-9301-1

[20] N. Okada, T. Hasebe, M. Iwasaki, N. Tamura, S. Akashi-Tanaka, T. Hojo, et al. Metaplastic carcinoma of the breast. Human pathology. 2010; 41: 960-970. PMid: 20236684. http://dx.doi.org/10.1016/j.humpath.2009.11.013

[21] K. Kurian, A. Al-Nafussi. Sarcomatoid/metaplastic carcinoma of the breast: a clinicopathological study of 12 cases. Histopathology. 2002; 40: 58-64. PMid: 11903598. http://dx.doi.org/10.1046/j.1365-2559.2002.01319.x

[22] Z. Toumi, C. Bullen, A. Tang, N. Dalal, S. Ellenbogen. Metaplastic breast carcinoma: a case report and systematic review of the literature. Pathology international. 2011; 61: 582-588. PMid: 21951667. http://dx.doi.org/10.1111/j.1440-1827.2011.02698.x

[23] I. Chen, C. Lin, C. Huang, H. Lien, C. Hsu, W. Kuo, et al. Lack of efficacy to systemic chemotherapy for treatment of metaplastic carcinoma of the breast in the modern era. Breast cancer research and treatment. 2011; 130: 345-351. PMid: 21792625. http://dx.doi.org/10.1007/s10549-011-1686-9

[24] B. Hennessy, S. Giordano, K. Broglio, Z. Duan, J. Trent, T. Buchholz, et al. Biphasic metaplastic sarcomatoid carcinoma of the breast. Annals of Oncology. 2006; 17: 605-613. PMid: 16469754. http://dx.doi.org/10.1093/annonc/mdl006

[25] N. Tamura, T. Kinoshita. A Case of Metaplastic Carcinoma of the Breast. Japanese journal of clinical oncology. 2011; 41: 1045-1045. PMid: 21803877. http://dx.doi.org/10.1093/jjco/hyr107 
[26] T. Nagao, T. Kinoshita, T. Hojo, H. Tsuda, K. Tamura, Y. Fujiwara. The differences in the histological types of breast cancer and the response to neoadjuvant chemotherapy: the relationship between the outcome and the clinicopathological characteristics. The Breast. 2012; 21: 289-295. PMid: 22277312. http://dx.doi.org/10.1016/j.breast.2011.12.011

[27] H.J. Shin, H.H. Kim, S.M. Kim, D.B. Kim, M.-J. Kim, G. Gong, et al. Imaging features of metaplastic carcinoma with chondroid differentiation of the breast. American Journal of Roentgenology. 2007; 188: 691-696. PMid: 17312055. http://dx.doi.org/10.2214/AJR.05.0831

[28] W.H. Tseng, S.R. Martinez. Metaplastic breast cancer: to radiate or not to radiate? Annals of surgical oncology. 2011 ; $18: 94-103$. PMid: 20585866. http://dx.doi.org/10.1245/s10434-010-1198-6

[29] G. Dave, H. Cosmatos, T. Do, K. Lodin, D. Varshney. Metaplastic carcinoma of the breast: a retrospective review. International Journal of Radiation Oncology Biology Physics. 2006; 64: 771-775. PMid: 16246496. http://dx.doi.org/10.1016/j.ijrobp.2005.08.024

[30] S.Y. Bae, S.K. Lee, M.Y. Koo, S.M. Hur, M.-Y. Choi, D.H. Cho, et al. The prognoses of metaplastic breast cancer patients compared to those of triple-negative breast cancer patients. Breast cancer research and treatment. 2011; 126: 471-478. PMid: 21287362. http://dx.doi.org/10.1007/s10549-011-1359-8

[31] M.A. Helvie, M. Rebner, E.A. Sickles, H.A. Oberman. Calcifications in metastatic breast carcinoma in axillary lymph nodes. AJR. American journal of roentgenology. 1988; 151: 921-922. PMid: 2845762. http://dx.doi.org/10.2214/ajr.151.5.921

[32] F.M. Blows, K.E. Driver, M.K. Schmidt, A. Broeks, F.E. van Leeuwen, J. Wesseling, et al. Subtyping of breast cancer by immunohistochemistry to investigate a relationship between subtype and short and long term survival: a collaborative analysis of data for 10,159 cases from 12 studies. PLoS medicine. 2010; 7: e1000279. PMid: 20520800. http://dx.doi.org/10.1371/journal.pmed.1000279

[33] W.D. Foulkes, J.-S. Brunet, I.M. Stefansson, O. Straume, P.O. Chappuis, L.R. Bégin, et al. The prognostic implication of the basal-like (cyclin Ehigh/p27low/p53+/glomeruloid-microvascular-proliferation+) phenotype of BRCA1-related breast cancer. Cancer research. 2004; 64: 830-835. PMid: 14871808. http://dx.doi.org/10.1158/0008-5472.CAN-03-2970

[34] A.A. Hashmi, M.M. Edhi, H. Naqvi, N. Faridi, A. Khurshid, M. Khan. Clinicopathologic features of triple negative breast cancers: an experience from Pakistan. Diagnostic pathology. 2014; 9: 43. PMid: 2458127. http://dx.doi.org/10.1186/1746-1596-9-43

[35] J.S. Reis-Filho, F. Milanezi, D. Steele, K. Savage, P.T. Simpson, J. Nesland, et al. Metaplastic breast carcinomas are basal-like tumours. Histopathology. 2006; 49: 10-21. PMid: 16842242. http://dx.doi.org/10.1111/j.1365-2559.2006.02467.x

[36] S. Leibl, F. Moinfar. Metaplastic breast carcinomas are negative for Her-2 but frequently express EGFR (Her-1): potential relevance to adjuvant treatment with EGFR tyrosine kinase inhibitors? Journal of clinical pathology. 2005; 58: 700-704. PMid: 15976335. http://dx.doi.org/10.1136/jcp.2004.025163

[37] B. Dunne, A.H. Lee, S.E. Pinder, J.A. Bell, I.O. Ellis. An immunohistochemical study of metaplastic spindle cell carcinoma, phyllodes tumor and fibromatosis of the breast. Human pathology. 2003; 34: 1009-1015.

http://dx.doi.org/10.1053/S0046-8177(03)00414-3

[38] M. Velasco, G. Santamaría, S. Ganau, B. Farrús, G. Zanón, C. Romagosa, et al. MRI of metaplastic carcinoma of the breast. American Journal of Roentgenology. 2005; 184: 1274-1278. PMid: 15788609. http://dx.doi.org/10.2214/ajr.184.4.01841274

[39] W.T. Yang, B. Hennessy, K. Broglio, C. Mills, N. Sneige, W.G. Davis, et al. Imaging differences in metaplastic and invasive ductal carcinomas of the breast. American Journal of Roentgenology. 2007; 189: 1288-1293. PMid: 18029860. http://dx.doi.org/10.2214/AJR.07.2056

[40] S.K. Patterson, J.A. Tworek, M.A. Roubidoux, M.A. Helvie, H.A. Oberman. Metaplastic carcinoma of the breast: mammographic appearance with pathologic correlation. AJR. American journal of roentgenology. 1997; 169: 709-712. PMid: 9275883.

http://dx.doi.org/10.2214/ajr.169.3.9275883 